\title{
REVIEW
}

\section{Mass-Scaled Rates of Respiration and Intrinsic Growth in Very Small Invertebrates}

\author{
Karl Banse \\ School of Oceanography WB-10, University of Washington, Seattle, Washington 98195 , USA \\ and \\ Skidaway Institute of Oceanography, University System of Georgia, Savannah, Georgia 31406, USA
}

\begin{abstract}
This review compares rates of oxygen uptake and intrinsic growth of very small invertebrate species near $20^{\circ} \mathrm{C}$ with those of larger invertebrate and unicellular animals by means of the allometric relation (rate $\alpha \mathrm{M}^{b}$ where $\mathrm{M}=$ mass). Respiration rates of small specjes of major invertebrate taxa are lower than those extrapolated for larger invertebrates but generally higher than those for protozoans of the same mass. Mass-specific rates of small metazoans and protozoans are lowered accordingly; therefore, their total food and oxygen consumption is likely to be small relative to that of large metazoans in average pelagic and benthic communities where most of the biomass is in large animals. The exponent $b$ for each of the major taxa treated here tends to be near 0.75 rather than close to unity. Thus, the respiration of these taxa is about as mass dependent as that of large animals. Metabolic reduction is set in relation to small adult size as such, and previous inferences about the phylogeny of metazoan metabolism do not seem warranted any more. Intrinsic growth rates of benthic rotifers and marine free-living nematodes are not only lower than those extrapolated for larger invertebrates but fall below those for protozoans of the same mass. Among benthic harpacticoid copepods, a slight reduction relative to mass-scaled large invertebrates is indicated. Pelagic freshwater rotifers do not exhibit this reduction. Intrinsic growth rates of pelagic freshwater cladocerans are independent of adult mass and not clearly higher than those of the few pelagic copepods studied. Future research into the physiological reasons for mass dependence of metabolism and growth should focus on unicellular or small multicellular species because of their short generation times.
\end{abstract}

\section{INTRODUCTION}

This paper sets out from two earlier, unrelated hypotheses concerning the evolution of metazoan metabolism and the protection from invertebrate predation provided by very small body size. It reviews laboratory measurements of rates of respiration and optimal growth, largely of aquatic species. It seeks to put such data into a framework by which rule and exception may be recognized and which is amenable to future first-principle explanations of a physiological or ecological nature. The main result is that the smallest invertebrates are not simply scaled-down versions of the larger species in respect to oxygen uptake and intrinsic growth but that large reductions are apparent. These are related to small body size (mass) as such, rather than to the phylogeny of metazoan metabolism. The paper does not formally test the predation refuge hypothesis but provides indirect support by demonstrating lowered rates of respiration and intrinsic growth which were previously inferred to be possible evolutionary consequences of lowered predation and hence, mortality.

The dependence of rates of respiration (q) and intrinsic growth $\left(r_{\mathrm{m}}\right)$ on body mass is described by power functions, $\mathrm{q}=a \mathrm{M}^{b}$ and $\mathrm{I}_{\mathrm{m}}=c \mathrm{M}^{-d}$, where $\mathrm{M}=$ body mass, and a through $d=$ coefficients; $a$ and $c$ will be called proportionality coefficients. The Exponent $b$ in the respiration equation for between-species comparisons is close to 0.75 for most organisms (Hemmingsen, 1960 ; for the mass-specific rate $\mathrm{q} / \mathrm{M}, \quad b$ is -0.25 ). McMahon (1973) and Blum (1977) presented arguments for the derivation of exponents of 0.75 from first principles (cf. Platt and Silvert, 1981, for more recent work). Further, the proportionality Coefficient $a$ for poikilotherms is about 8 times that for unicellular 
organisms (Zeuthen, 1953; Hemmingsen, 1960) so that a small metazoon should have that much higher a metabolic rate than a protozoon of the same body mass.

Respiratory rates of very small invertebrates, however, seem to be smaller than would be the case were they scaled-down versions of large poikilotherms (Zeuthen, 1953; Hemmingsen, 1960); yet the rates are still higher than those of unicellular organisms when differences in body mass are taken into account (Fig. 1). Zeuthen (1953) suggested that these intermediate respiration rates follow a mass dependence

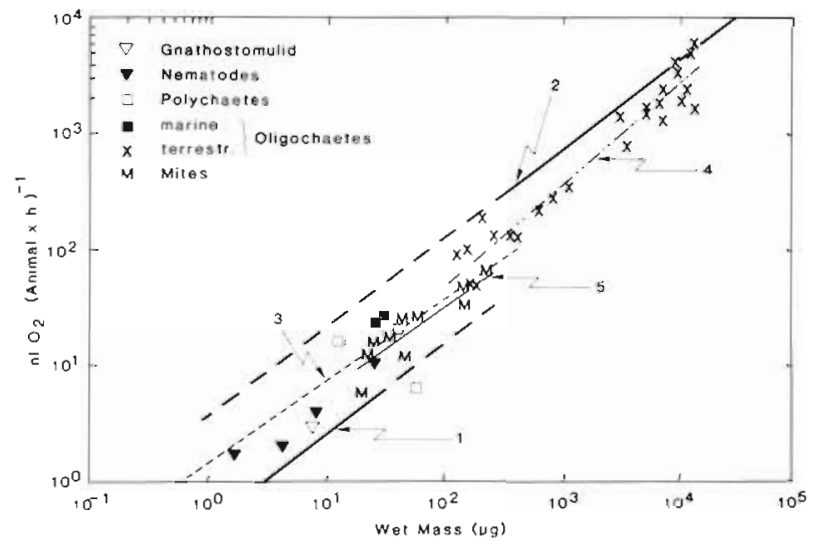

Fig. 1. Rate of oxygen uptake as function of wet body mass at $20^{\circ} \mathrm{C}$. (1) Unicellular species; (2) large poikilotherms (both from Hemmingsen 1960; broken sections, extrapolated); (3) nematodes (from Klewkowski et al., 1972; 5 new values not included in regression); (4) enchytraeid oligochaetes, large specimens (see 'Methods', 'Results'); (5) mites (see Methods'). See 'Methods' for other, individual data points

with an Exponent $b \sim 0.95$; Prosser (1973: p.194) accepted this view. Zeuthen (1953; see also Zeuthen, 1970) further thought that near-direct dependence ( $b$ close to unity) reflects the phylogenetic transition from the relatively low protozoan to the high metazoan rates. He supported his opinion by observations on an apparent ontogenetic recapitulation of phylogeny (cf. additional ontogenetic data on oxygen uptake in Wilkie, 1977).

In contrast, Klekowski et al. (1972) calculated an Exponent $b$ of 0.72 for tree-living nematodes and some nematodes parasitizing plants (Fig. 1). For Collembola ranging from about 0.5 to $2000 \mu \mathrm{g}$ dry mass, I estimate an exponent near 0.75 from Fig. 12 in Petersen (1981, for $10^{\circ} \mathrm{C}$; see also earlier calculations of 0.74 by Zinkler and 0.73 by Persson and Lohm [cited from Petersen, 1981]). Atkinson (1976), using largely the same data base as Klekowski et al., noted that the proportionality Coefficient a fell between Hemmingsen's (1960) values for unicellular and poikilothermic organisms. In her not formally published thesis, Dewey (1976) also recalculated literature data for very small invertebrates, separating them into 3 phyla. She observed that the $b$ values did not differ significantly from 0.75 , and that the a values were intermediate between those for Hemmingsen's equations for unicellular and poikilothermic organisms. Dewey confirmed Hemmingsen's equation for unicellular forms with published, more critically chosen measurements. The present paper re-evaluates and expands Dewey's data base for metazoans but arrives at results similar to hers.

An explanation for the lowered respiratory rates of the smallest invertebrates, different from that by Zeuthen (1953, 1970), was proposed by Banse and Mosher (1980). We demonstrated that the P/B quotients (production/mean biomass, on an annual basis) of temperate field populations of species from 5 major invertebrate phyla, including 4 of the major classes of arthropods, can be scaled by body mass at first maturity with 1 allometric relation. However, the $\mathrm{P} / \mathrm{B}$ of the smallest planktonic and benthic invertebrates are appreciably lower than calculated from that equation. Assuming that population biomass is relatively constant from year to year, we noted that lower production is equivalent to lower mortality. On this basis, we postulated that very small body size (as in phytoplankton, rotifers, copepod nauplii, and meiobenthic nematodes) provides refuge from predation, thus reducing a major cause of mortality. Although not explicitly stated by us, the predators would be invertebrates. We also remarked that small animal species would possess high specific growth rates requiring very high daily rations (e. g. equal to body mass) so that there must be selection pressure to reduce this demand. Lowered mortality resulting from small size would permit lowered population growth rates. Now, if these were accompanied by lowered specific growth rates (cf. observed lower population $\mathrm{P} / \mathrm{B}$ ), rations would on the average be smaller and may be accompanied by lowered specific respiratory rates, owing to a lesser expenditure of energy for food gathering and biosynthesis. This explanation refers to small size as such, is - in contrast to Zeuthen's attempt - not restricted to the primitive metazoan phyla, and is strengthened here by the inclusion of adult crustaceans.

Refuge from predation which permits lowered population growth rates in the field might be reflected in lowered intrinsic growth rates. Therefore, the mass dependence of optimal (laboratory-determined) intrinsic growth rates $\left(\mathrm{r}_{\mathrm{m}}\right)$ of very small metazoans is also reviewed. As with the data on oxygen uptake, taxa were chosen on the basis of availability of observations. Previously, Fenchel (1974) showed that the Exponent $d$ of the allometric equation for such mass dependence is -0.275 for unicellular and poikilothermic forms (not significantly different from -0.25 , see Banse, 1979); the proportionality Coefficient $c$ for the 
latter is roughly twice that for the former, in analogy to the discussed respiration equations. Elsewhere, I review the mass dependence of optimal growth rates of unicellular algae and compare it with that of ciliates (Banse, 1982). That paper as well as the present one suggests that the rules of mass dependence of $r_{m}$ are not so obvious as they seemed a few years ago. However, small metazoans in the aquatic benthic realm do exhibit intrinsic growth rates materially reduced relative to those calculated by the equation for larger metazoans.

A brief section at the end treats net growth efficiency. It combines between-species equations for oxygen which are largely based on measurements on (adult) specimens, with the intrinsic growth rate which is a population parameter. The section illuminates the present inadequacy of the data base alluded to earlier in the review.

Because this paper depends entirely on experimental observations by others, an extensive methods section describes the criteria and conversion factors employed during extracting the data. The intent is not only to list the values but to permit others to check the selection on which the results are based.

\section{METHODS}

\section{Body Mass}

Wet mass was used for Figs. 1 and 4 as most of the original data were in this form. For simplicity, a density of 1.0 was assumed when converting body volume to wet mass. Dry mass was utilized in Figs. 2, 3 and 5 to facilitate future reference. For some rotifers, dry mass was estimated from their protein content in Pourriot and Deluzarches (1970). For 1 rotifer, the nematodes, and the enchytraeids, dry mass was assumed to be $15 \%$ of the wet mass. The wet masses of 2 polychaetes, Hesionides arenaria and Stygocapitella subterranea (Fig. 1), are 15 to $18 \mu \mathrm{g}$ and 60 to $80 \mu \mathrm{g}$, respectively ( $\mathrm{P}$. Lasserre, in litt., for Lasserre and Renaud-Mornant, 1973). Dry mass of cladocerans at first reproduction (Fig. 5), rarely given in the original papers (except Smith, 1963), was usually computed from the formulae of Dumont et al. (1975) from length at first reproduction, either as in the original articles (from references 22, 24, 28, and 45 in Lynch, 1980: Table 1), or as in Lynch (1980: Table 1; none for Moina reticulata), and Allan and Goulden (1980: Fig. 7, for Winner and Farrell, 1976). The average adult cladoceran body mass was calculated in the same manner from the mean of the body mass at first reproduction and its maximal value. The wet mass of cladocerans (Fig. 3) was taken to be 6.4 times this dry mass, as averaged from Richman (1958: Table 7), Dumont et al. (1975: p 84), and Pavlova (2 species, as cited by Ivleva, 1980: p. 43). The wet mass of copepods was obtained by multiplying the dry mass somewhat arbitrarily by 5 (Curl, 1962; B. W Frost, pers. comm.). The wet mass of Paraleptastacus spinicauda studied by Lasserre and Renaud-Mornant (1973) is 3.0 to $3.5 \mu \mathrm{g}$ (P. Lasserre, in litt.). Dry mass values for the harpacticoids Hastigerella leptoderma and Nannopus palustris, investigated by Vernberg et al. (1977) and kindly provided by B. C. Coull (in litt.), are $2.2 \mu \mathrm{g}$ and $2.4 \mu \mathrm{g}$, respectively.

\section{Rates of Oxygen Uptake}

Most of the oxygen consumption rates were determined at $20^{\circ} \mathrm{C}$ but a few measured close to this temperature were converted using Krogh's (1916) standard curve. To obtain the rate for a particular nematode species from the observations by Wieser and Kanwisher (1961) and Teal and Wieser (1966), as well as for most rotifers and enchytraeids, the logarithms of the median masses among the individual experiments were entered into regression equations of log (massspecific rate of oxygen uptake) on log (mass) rather than using arithmetic averages as was necessary for some species. The data sources are as follows.

Pelagic rotifers: Females of 5 species were studied by Pourriot and Deluzarches (1970) and Pourriot (1973), and 1 by Ruttner-Kolisko (1972) and Doohan (1973). Of Doohan's measurement, the respiration of ovigerous females was used but the oxygen uptake by eggs subtracted.

Free-living nematodes: Individual data were read from figures in Wieser and Kanwisher (1961) and Teal and Wieser (1966; J. M. Teal confirmed that the measurements were performed at $20^{\circ} \mathrm{C}$ ). The rates used by Ott and Schiemer. (1973) were kindly provided by $F$. Schiemer. Values were also read from figures in Wieser and Kanwisher (1960) and Atkinson (1973; Enoplus brevis, at 135 torr); for the latter 2 papers, the masses of large specimens were selected. Means for Panagrolaimus rigidus, measured by Klekowski and coworkers, were taken from Schiemer and Duncan (1974) and for 2 other species from Wieser and Schiemer (1977). The remaining data came from the summary by Klekowski et al. (1972: Table II), omitting plant parasites and species No. 2 and 17 (the latter 2 because of marked inconsistencies between body mass, respiration, and specific respiration values) Entered individually in Fig. 1, but not included in the regression calculation, were the data for large specimens of 5 marine nematodes, read from plots of respiration on body volume by Warwick and Price (1979) of which I became aware only when completing the 
manuscript. Very recent data (Laybourn, 1979; Warwick, 1981) in papers referred to in other contexts, were not depicted.

Enchytraeids and soil mites: The mass-specific rates for oligochaetes were read from the figures in Overgaard-Nielsen (1961) and O'Connor (1963, 1976; values with labeling errors on axes omitted). These data were partially used also by Dewey (1976). The rates for the oribatid mites were taken from Luxton (1975: Appendix 2).

Other meiobenthos: Two marine oligochaetes were studied by Lasserre (1971: Fig. 6), 1 mystacocarid by Lasserre and Renaud-Mornant (1971), and 2 polychaetes and 1 copepod by Lasserre and RenaudMornant (1973). Two gnathostomulids were investigated by Schiemer (1973), the polychaete Manayunkia estuarina by Price and Warwick (1980), 1 species each of harpacticoid copepods by Lasker et al. (1970) and Teare and Price (1979; laboratory-reared animals), and 2 species each by Coull and Vernberg (1970) and Vernberg et al. (1977). A regression equation was not computed for the harpacticoids since most of the habitat and experimental temperatures deviated greatly from $20^{\circ} \mathrm{C}$; values in Fig. 2 are for illustration only; they do refer to $20^{\circ} \mathrm{C}$.

\section{Intrinsic Growth Rates $\left(\mathrm{r}_{\mathrm{m}}\right)$}

Because most data for metazoans were not compiled previously, more detail is provided here than in the section on respiration. Rates are based on laboratory work between $18^{\circ}$ and $20^{\circ} \mathrm{C}$ unless otherwise noted. Maximal values, or means for multiple measurements by one author, were taken from the literature thereby neglecting lower values except for the cladocerans (Fig. 5). Thus, observed differences in $r_{m}$ within species were regarded as principally caused by culture conditions rather than genetic variation among collections from different sites (for such genetic variability even within sites among rotifers, cf. King, 1972; Gilbert, 1976: Clones $12 \mathrm{C} 1$ and $10 \mathrm{C} 6$ ). Only the newlycompiled values for 4 rotifers and 5 copepods are based on life tables (see also remarks under 'Cladocerans'). The sources or methods of approximation for the other species are listed below. Judging from the criteria proposed by Laughlin (1965: Fig. 5) for estimating the accuracy of estimates of $\mathrm{r}_{\mathrm{m}}$ most of the intrinsic growth rates not based on life tables, but not signified here as rough approximations, are likely to be less than $10 \%$ below the true $r_{m}$. The letters $b$ and $p$ following the names of rotifers and copepods signify benthic or planktonic modes of life; the cladocerans are all planktonic.

Hydroids: Protohydra leuckarti: $\mathrm{r}_{m}=0.078 \mathrm{~d}^{-1}$ (Heip,
1977). Volume and hence wet mass of 2 to $9 \mu \mathrm{g}$ estimated from drawings in K. Muus (1966: Fig. 1a) and B. Muus (1967: Fig. 27). To combine data from 2 sites may lead to large errors (R. M. Warwick, in litt.) but these are unlikely to alter the position of the species in Fig. 4 so drastically that my argument is affected.

Rotifers: Pre-1976, accurate $r_{m}$ values for planktonic species were chosen in consultation with J. M. Dewey (cf. Dewey, 1976: Table 2; not checked against Laughlin, 1965) who also gave advice on the body masses. Asplanchna girodi $(\mathrm{p}): \mathrm{r}_{\mathrm{m}} \sim 0.52 \mathrm{~d}^{-1}$; wet mass, $14.8 \mu \mathrm{g}$ (Robertson and Salt 1981; both values, read from figures, are apparently slight underestimates because of non-saturating food level, cf. their Figs. 5 and 8 ). A. sieboldi (p): $\mathrm{r}_{\mathrm{m}}=0.58 \mathrm{~d}^{-1}$; wet mass, $25 \mu \mathrm{g}$ (both geometric means, for saccate and campanulate morphotypes, Clone $12 \mathrm{C} 1$, in Gilbert, 1976; values reduced from $22^{\circ} \mathrm{C}$ assuming a $Q_{10}$ of 2.0 ; dry masses multiplied by 6.6). Brachionus calyciflorus (p): $\mathrm{r}_{\mathrm{m}}=1.0$ $\mathrm{d}^{-1}$ (Galkovskaya, 1963); wet mass, $5 \mu \mathrm{g}$ (1.6 $\mu$ used in respiration equation). B. plicatilis $(\mathrm{p}): \mathrm{r}_{\mathrm{m}}=0.99 \mathrm{~d}^{-1}$ (Ruttner-Kolisko, 1970, for $17 \% \mathrm{~S}$ ); wet mass, $1.5 \mu \mathrm{g} .8$. rubens ( $p$ and epizooic): $r_{m}=1.14 d^{-1}$ (Pilarska, 1972); wet mass, $1.1 \mu \mathrm{g}$. Euchlanis dilatata $(\mathrm{p}): \mathrm{r}_{\mathrm{m}}=1.22 \mathrm{~d}^{-1}$ (reduced from $22^{\circ} \mathrm{C}$ value by King, 1967, assuming a $\mathrm{Q}_{10}$ of 2.0 ); wet mass, $2.7 \mu \mathrm{g}$. Lecane tenuiseta (b): $\mathrm{r}_{\mathrm{m}}=0.228 \mathrm{~d}^{-1}$ (Hummon and Bevylheimer, 1980); wet mass, $0.14 \mu \mathrm{g}$ (from dimensions kindly provided by W. D. Hummon, in litt.)

Crude estimates were attempted for 3 species but mortality before reproduction was neglected (only 1 , with estimated mass, entered in Fig. 4). Epiphanes senta $(p): I_{m}$ of very roughly $0.7 \mathrm{~d}^{-1}$ for amictic, and up to $1.2 \mathrm{~d}^{-1}$ for unfertilized mictic females, for 16 to $17^{\circ} \mathrm{C}$, based on Ferris (1932), using a pre-fecund period of $65 \mathrm{~h}$, the reported egg-laying rates, and assuming varying mean generation times of $65 \mathrm{~h}$ plus 1/3, and $1 / 2$ of the mean fecund period. Lecane inermis (b): based on Miller (1931), I figured $r_{m}$ values between 0.33 and 0.38 $\mathrm{d}^{-1}$ from the observed rate of egg-laying of $24(7.5 \mathrm{~d})^{-1}$, the first egg deposition by the end of the third day, and varying lengths of the fecund period, up to the reported mean of $5.9 \mathrm{~d}$ (Miller, 1931: Table 10); the true $\mathrm{I}_{\mathrm{m}}$ may be higher by almost $10 \%$ (Laughlin, 1965: Fig. 5). Wet mass was estimated as $0.35 \mu \mathrm{g}$ from Miller (1931: Figs. 2 and 3). Proales sordida (b?): $r_{m}$ may be unity or somewhat higher, to judge from Jennings and Lynch (1928: Tables 15, 18) for Population E for which the most complete data are available. Also this rate may underestimate the true $r_{m}$ by almost $10 \%$. With a length of about $0.3 \mathrm{~mm}$ and a near-cylindrical crosssection, the species might be somewhat heavier than the largest rotifer in Fig. 4.

Note that the laboratory data for rotifers used here refer exclusively to amictic females. Probably, this 
restriction to parthenogenetic reproduction will not bias the conclusions (King, 1970).

Free-living Nematodes: Except the first-named, saprophytic species, all others can be regarded as meiofauna members; only Plectus palustris lives in freshwater. Caenorhabditis briggsae: $\mathrm{r}_{\mathrm{m}}=1.136 \mathrm{~d}^{-1}$; wet mass, $0.50 \mu \mathrm{g}$ (both values at $5 \times 10^{10}$ bacteria $\mathrm{ml}^{-1}$, Schiemer 1982a, b). Chromadorina germanica: $r_{m}=0.15 d^{-1}$ (Tietjen and Lee, 1977: Fig. 1, for $26 \%$ S); volume and, thus, wet mass of 0.6 to $0.7 \mu \mathrm{g}$ from de Coninck and Schuurmans Steekhoven (1933: Figs. 49-51) and Andrassy's formula as in Prejs (1977). Diplolaimella chitwoodi: $\mathrm{r}_{\mathrm{m}}=0.27 \mathrm{~d}^{-1}$ (mean of 5 optimal values in Findlay, 1982: Table 1); wet mass, $0.4 \mu \mathrm{g}$ (Findlay, 1981). Diplolaimelloides bruciei: $r_{m}=0.23$ $\mathrm{d}^{-1}$; wet mass, $0.35 \mu \mathrm{g}$ (Warwick, 1981). Diplolaimella sp. and Monhystera disjuncta, $\mathrm{r}_{\mathrm{m}}=0.114$ and $0.116 \mathrm{~d}^{-1}$; wet masses, 1.13 and $1.76 \mu \mathrm{g}$, respectively ( $\mathrm{r}$ determined by Alongi and Tietjen, 1980; reduced here to $20^{\circ} \mathrm{C}$ assuming a linear decrease with temperature [Heip, 1977], r at $0^{\circ} \mathrm{C}$ taken to be zero; wet masses, pers. comm. J. H. Tietjen). Oncholaimus oxyuris: $\mathrm{r}_{\mathrm{m}}=0.022 \mathrm{~d}^{-1}$; wet mass, $20 \mu \mathrm{g}$ (Heip et al., 1978).

Crude estimates (not entered in Fig. 4) were attempted for the synthetic population of Chromadorita tenuis designed by Gerlach (1971: Fig. 2) and Plectus palustris based on measurements in Schiemer et al. (1980); I used the approximation of $r_{m}=\ln R_{o} / T$, where $R_{o}=$ net reproductive rate (i.e. number of female eggs); $T=$ generation time (Laughlin, 1965); mortality is taken to be zero. Assuming for the former a sex ratio of $1: 1$ and a mean $\mathrm{T}$ of $32 \mathrm{~d}$ (see experimental data by $\mathrm{v}$. Thun in Gerlach, 1971), an $r_{m}$ of $0.072 \mathrm{~d}^{-1}$ is obtained; wet mass, $1 \mu \mathrm{g}$. For the latter, parthenogenetic species, with a time span of $15 \mathrm{~d}$ from egg to egg at food level 10K, and a gradual increase of egg laying rate during the first five $\mathrm{d}, \mathrm{r}_{\mathrm{m}}$ is about 0.23 to $0.26 \mathrm{~d}^{-1}$; wet mass, $1.5 \mu \mathrm{g}$. The same approximating formula was applied to the 6 species studied by $v$. Thun (see Kinne, 1977: Table 5-33), using the minimal rather than the mean generation time, the average egg number, and a sex ratio of $1: 1$. This yields rates of 0.10 to $0.12 \mathrm{~d}^{-1}$ for 5 , and of 0.03 $\mathrm{d}^{-1}$ for 1 species. Among the 5 species, the value thus obtained for Monhystera disjuncta is 0.12 rather than the more accurate of $0.072 \mathrm{~d}^{-1}$ calculated above, while that for $M$. disjuncta is 0.115 , as in Alongi and Tietjen (1980).

Pelagic Cladocerans: The $\mathrm{r}_{\mathrm{m}}$ data for Fig. 5 (referring to parthenogenetic reproduction only), were taken from Lynch (1980: Table 2) without checking on the source material, and from Winner and Farrell (1976). Daphnia pulicaria in Lynch (1980: Table 2) was regarded as a synonym of $D$. pulex, following Frank et al. (1957).

Copepods: Euterpina acutifrons (p): $\mathrm{r}_{\mathrm{m}}=0.179 \mathrm{~d}^{-1}$
(Zurlini et al., 1978 ; original value for $18^{\circ} \mathrm{C}$, multiplied by $20 / 18$ based on Heip's observation of 1977 of a linear increase of $r$ with temperature); dry mass, $2.3 \mu \mathrm{g}$. Calanus pacificus (p) and Pseudocalanus sp. (p): calculated by B. W. Frost (pers. comm.) from life tables for the first 3 clutches of eggs produced at $12^{\circ} \mathrm{C}$, assuming no mortality but a sex ratio of $1: 1$ (although females are slightly favored), and converting to $15^{\circ} \mathrm{C}$ (for Fig. 5b) by a $\mathrm{Q}_{10}$ of 2.0 . The $\mathrm{r}_{\mathrm{m}}$ values and dry masses are 0.18 $\mathrm{d}^{-1}$ and $250 \mu \mathrm{g}$ for the former, and $0.11 \mathrm{~d}^{-1}$ and $16 \mu \mathrm{g}$ for the latter; the consideration of additional egg laying does not alter the calculated $\mathrm{r}_{\mathrm{m}}$ greatly. Gladioferens imparipes $(\mathrm{p}): \mathrm{r}_{\mathrm{m}}=0.207 \mathrm{~d}^{-1}$ (Rippingale and Hodgkin, 1974); dry mass of $12 \mu \mathrm{g}$ ( $=60 \mu \mathrm{g}$ wet) from entering metasome length at $20^{\circ} \mathrm{C}$ (Rippingale and Hodgkin, 1974 ) into Robertson's (1968) formula for Centropages (model based on Thomson, 1946). Tachidius discipes (b) : $r_{m}=0.186 d^{-1}$ (Heip and Smol, 1976); wet mass, $10 \mu \mathrm{g}$ (Heip, 1978). Tisbe holothuriae (b): $\mathrm{r}_{\mathrm{m}}=0.23 \mathrm{~d}^{-1}$, wet mass, $33 \mu \mathrm{g}$ (Gaudy and Guérin, 1978; original $r_{m}$ value for $18^{\circ} \mathrm{C}$ multiplied by $20 / 18$, as for Euterpina, above). The $r_{m}$ determination of $0.30 \mathrm{~d}^{-1}$ for $19^{\circ} \mathrm{C}$ by Gaudy and Guérin (1977), likewise based on a life table, and Gaudy et al. (1982) were neglected because values for body mass could not be found. I made crude estimates of $\mathrm{I}_{\mathrm{m}}$ values of near 0.07 and $0.15 \mathrm{~d}^{-1}$ for Microarthridion littorale and Tigriopus japonicus. For the former, 20 eggs for each of 3 clutches laid $3 \mathrm{~d}$ apart, a time from egg to egg of $42 \mathrm{~d}$, and a 1:1 sex ratio were assumed (Palmer, 1980; Palmer and Coull, 1980). For the latter, an egg-to-egg generation time of $21 \mathrm{~d}$ with 30 eggs per batch, laid $2.5 \mathrm{~d}$ apart, and a $1: 1$ sex ratio were used (Takano, 1971), probably giving an overestimate of $r$.

\section{Calculations}

The dependence of respiration on body mass was calculated by linear, least-square regression technique from the log-transformed equation, $\log q=\log$ $a+b \cdot \log \mathrm{M}$, with $q$ in $\mathrm{nl} \mathrm{O}_{2} \mathrm{~h}^{-1}$ and $\mathrm{M}$ in $\mu \mathrm{g}$. The intrinsic growth rate was handled in the same way. Statements about statistical significance are at the level of $p=0.05$.

For the purpose of illustration, the regression line by Fenchel (1974) for the mass dependence of $r_{m}$ in 10 poikilothermic animals (essentially, laboratory-based data) was entered in Fig. 4. Also calculated was an invertebrate line using the same data, but excluding the cod because Banse and Mosher (1980) demonstrated that the specific production rates (on an annual basis) of fish are appreciably higher than those of invertebrates. As a result, the coefficient of determination $\left(\mathrm{R}^{2}\right)$ changed from 0.90 for poikilotherms, to 0.93 , and the exponent of the new line was lowered from 
-0.27 to -0.35 (C.I., -0.44 to -0.27 ). Equations for the same invertebrates after onitting first the rotifer and then the cladoceran both have exponents of -0.36 and practically identical intercepts as with the species $\left(R^{2}, 0.88\right.$ and $0.85 ; n=8$ and 7$)$. The line excluding the rotifer and cladoceran was entered in Fig. 4.

\section{RATES OF OXYGEN UPTAKE BY METAZOANS}

\section{Results}

The results are presented in 2 ways: Regression lines for small invertebrates with measurements of wet mass as the independent variable are compared in Fig. 1 with Hemmingsen's (1960) relations. Newer data. which have not been incorporated in the regression lines are added for a gnathostomulid, nematodes, polychaetes, and marine oligochaetes. In contrast, Fig. 2 and Table 1 present regression equations based on dry mass or on suitable conversions to dry mass.

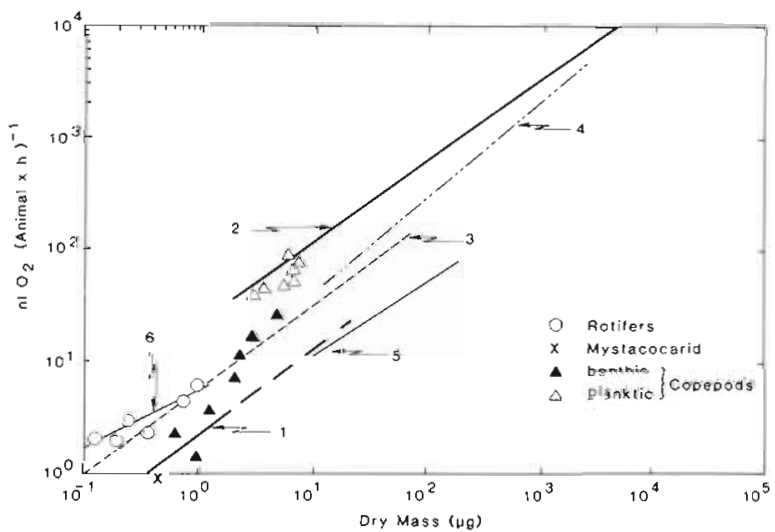

Fig. 2. Rate of oxygen uptake as function of dry body mass at $20^{\circ} \mathrm{C}$. (1) Unicellular eucaryotes (see Table 1 ; broken section extrapolated); (2) crustaceans (from Ivleva, 1980); (3) to (5) see Fig. $1 ;(6)$ rotifers (see Table 1 ). See 'Methods' for individual data points
These lines are compared with those for a comprehensive crustacean equation based on numerous new observations (Ivleva, 1980: Table 3, second-to-last equation) and the equation by Dewey (1976) for the endogenous respiration of eucaryotic, heterotrophic unicellular organisms (i.e. without uptake of nutritive material; Table 1). The incorporation of newer data for ciliates (Khlebovich, 1974; Laybourn and Finlay, 1976 [cf. comments in Fenchel, 1980]; Laybourn, 1977) would increase the variance but otherwise support Dewey's equation. Ivleva and Dewey's lines (Fig. 2) are similar to those for the 2 equations of Hemmingsen (Table 1) and suggest an about 9 -fold difference in the rate of oxygen uptake between crustaceans and unicellular organisms.

Figs. 1 and 2 span a mass range equivalent to that represented by voles and elephants. They illustrate and confirm Zeuthen's (1953) and Hemmingsen's (1960) observation that rates of oxygen uptake by metazoan taxa with small-sized species tend to fall between those of 'average' large invertebrates and of protozoans when differences in body masses are taken into account. The exception are mites (Fig. 2), displaced slightly below the unicellular line of Dewey (1976) because of their unusually low water content (about half the wet mass). Among the copepods, the reduction appears to hold only for benthic forms: Even the harpacticoid species with the highest rate of oxygen uptake (Fig. 2) exhibits only about half the rate of seven planktonic copepods of about the same mass which cluster around the lower end of Ivleva's line (Fig 2). In other words, the proportionality Coefficients $a$ of the equations for small metazoans are intermediate between those of larger invertebrates and of protozoans.

More importantly, statistics (Table 1) do not support the view of Zeuthen $(1953,1970$; cf. Hemmingsen, 1960; Epp and Lewis, 1980) that respiratory mass dependence among small invertebrates is near-direct

Table 1. Relations between rate of oxygen uptake $\mathrm{q}, \mathrm{nl} \mathrm{O}_{2}$ (individual $\left.\times \mathrm{h}\right)^{-1}$, and bodily dry mass, $\mathrm{M}\left(\mu \mathrm{g}\right.$ ), at $20^{\circ} \mathrm{C}$. Coefficients for log-transformed equation, $q=a M^{b}$; C. I., confidence interval, $p=0.05$

\begin{tabular}{|c|c|c|c|c|c|c|c|}
\hline Group & $n$ & $\log a$ & & C. I. & $b$ & C.I. & $\mathrm{R}^{2}$ \\
\hline Nematodes & 62 & .73 & .64 & to .81 & .76 & .65 to .86 & .78 \\
\hline Rotifers & 6 & .72 & .55 & to .89 & .52 & .21 to .82 & .85 \\
\hline Enchytraeids & 27 & .74 & .53 & to .93 & .85 & .77 to .94 & .95 \\
\hline Mites & 10 & .38 & -.0 .9 & to .86 & .67 & .34 to .99 & .74 \\
\hline Unicellulars ${ }^{\circ}$ & 21 & .34 & .20 & to .48 & .74 & .66 to .82 & - \\
\hline Unicellulars “ & many & .43 & .21 & to $.65 \cdots$ & .76 & .72 to .80 & - \\
\hline Poikilotherms " & many & 1.29 & 1.15 & to $1.43^{\cdots} \cdot$ & .74 & .72 to .76 & - \\
\hline \multicolumn{8}{|c|}{ - Dewey (1976), only eucaryotes } \\
\hline
\end{tabular}


(i.e. Exponent $b$ is close to unity). Instead, it is more likely that the dependence follows that of all living things, i.e. around $20^{\circ} \mathrm{C}$, Exponent $b$ is indistinguishable from 0.75 . The trend for the few values for harpacticoid copepods in Fig. 2 suggest an exponent near unity but the data are neglected for this conclusion because few were actually determined at $20^{\circ} \mathrm{C}$ (see temperature dependence of $b$, below). As mentioned in the 'Introduction', exponents near 0.75 had been established previously for some of the groups in Table 1, as well as for Collembola.

\section{Discussion}

Invertebrates Versus Protozoans

Figs. 1 and 2 comprise data from a variety of phyla, including arthropods, which exhibit a lowered proportionality Coefficient $a$. Therefore, intermediate respiration rates are not restricted to primitive metazoans, contrary to Zeuthen's (1953) view mentioned in the 'Introduction'. I suggest instead that the reduction is related to small physical size as such and is the evolutionary consequence of the predation refuge suggested by Banse and Mosher (1980; cf. Banse, 1982, for rotifers): Reduced mortality in populations of small species permits lowered rates of production and hence, of ingestion rates and metabolism. There must be a premium on selection for lowered food requirements per unit body mass and time in organisms which have to consume daily the equivalent of approximately their own body mass, or more, in order to survive.

Because the metabolic reduction discussed here is not restricted to primitive metazoans, inferences like those by Zeuthen $(1953,1970)$ about the phylogeny of the metazoan metabolism which are based on such evidence, do not seem warranted any more. The new results, however, do not answer the related question why the larger, average adult metazoon operates on a metabolic level which surpasses that of a mass-scaled, average protozoon by 8 or 9 times. Small metazoan taxa as in Figs. 1 and 2 demonstrate that metazoans can occupy many habitats successfully, and with a great diversity of species, while being supported by rates of oxygen consumption that are 2 to only a few times larger than those of protozoans of the same mass. The higher metazoan metabolism has little to do with energy spent on movement. Note that the poikilotherm line in Fig. 1 and the nearly coinciding crustacean line in Fig. 2 are based on resting metabolism, to the degree that this exists or can be measured in invertebrates: the oxygen uptake in pelagic copepods was studied while they were slowly swimming. However, for the small species in Fig. 2, the energy expenditure for rapid movement adds only little to this 'resting' metabolism (Santmyer, 1956; Lasserre and RenaudMornant, 1971; McAllister, 1971: p. 107; Foulds and Roff, 1976; Klyashtorin and Kuz'micheva, 1976; however, $53 \%$ in Vernberg et al., 1977) so that the expense for slow swimming must be small indeed, relative to the maintenance metabolism. Therefore, most of the difference in metabolic rate between the pelagic copepods as representing large invertebrates and protozoans in Fig. 2 cannot be explained yet.

\section{Excretion Rates}

Metabolic rates other than respiration, e.g. of nitrogen excretion, must scale to body mass with the same exponent, since otherwise organisms of greatly differing size which feed on the same kind of food in terms of chemical constituents (e.g. phytoplankton or grass) would differ in their gross chemical composition. Indeed, of 4 comparisons of exponents of mass dependence for oxygen uptake and ammonium excretion by zooplankton (Ikeda, 1974), and 2 sets for planktonic crustaceans (Vidal and Whitledge, 1982) 4 pairs are almost identical, while 2 do not differ significantly and show trends opposed to each other; the dry masses range approximately from $10^{0}$ to $10^{5} \mu \mathrm{g}$. Also the directly-determined $\mathrm{C}: \mathrm{N}$ ratios in zooplankton, spanning almost the same size range, are not mass dependent (Ikeda, 1974); neither are those of rabbits and elephants. Hence, a picture quite similar to Fig. 2 must hold for the nitrogen and phosphorus excretion rates. Johannes (1964) though, reported a large change of exponents in equations for mass dependence of phosphorus excretion rates, from 0.67 in large to 0.33 in small animals, at about $1 \mathrm{mg}$ dry mass. I suggest that these observations were in error (see also comments on the experimental results by Taylor and Lean, 1981). Taylor and Lean further showed that uptake of phosphorus in such ciliates occurs principally by feeding. Therefore, independent of my above argument about similarity of exponents, I note that the high turnover rates of body phosphorus measured by Johannes in small animals (cause of the small Exponent $b$ ), e.g. of $14 \mathrm{~min}$ for a ciliate of about $0.4 \mathrm{ng}$ dry mass, are unlikely: the animals cannot nearly devour the equivalent of their own body weight in that time (cf. Fig. 2 in Fenchel, 1980).

\section{Mass-Specific Rates}

In ecological contexts, mass-specific rates are often a more useful tool than rates per animal. Accordingly, Fig. 3 illustrates the mass range from quite small 
pelagic or benthic ciliates to fair-sized pelagic copepods and cladocerans; the range includes much of the benthic meiofauna. The figure indicates that oxygen uptake and nutrient regeneration by ciliates in the

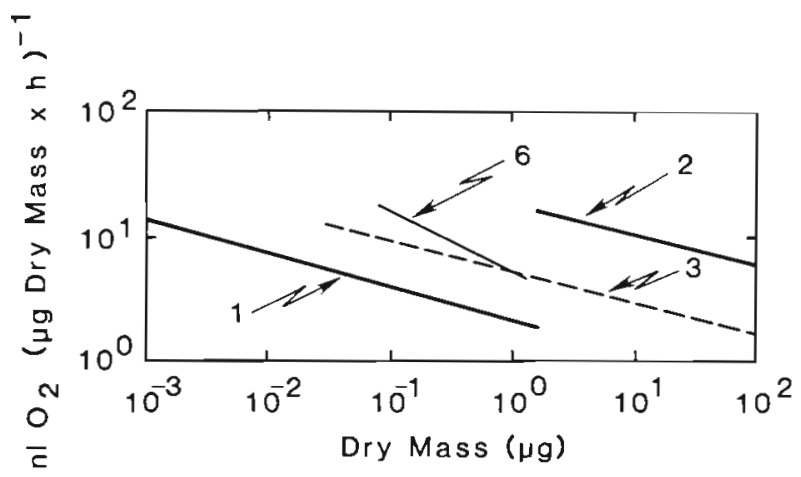

Fig. 3. Mass-specific rate of oxygen uptake as function of dry body mass at $20^{\circ} \mathrm{C}$. (1) Unicellular species; (2) crustaceans; (3) nematodes; (6) rotifers. For Lines 1, 2, and 6, see also Fig. 2 ; for Line 3, see Fig. 1

plankton approximately matches that by copepods only if the ciliates are all small and equal the total biomass of the copepods. Usually, of course, the ciliate biomass is only a fraction of the crustacean biomass. On independent grounds, I elsewhere commented on the long-standing issue of the role of ciliates in the marine pelagial and suggested that their food consumption is on the average much lower than that by copepods (Banse, 1982). A similar statement although with less confidence (Table 1) can be made for oxygen consumption by pelagic rotifers in relation to that by copepods or ciliates. Also in the benthos, the difference in proportionality Coefficients $a$ of the allometric equations will cause the meiofauna (e.g. nematodes) to be less important relative to the macrofauna than is often suggested. Likewise, the seeming importance of ciliates relative to the metazoan meiofauna (cf. Fenchel, 1978, and references therein) fades somewhat. The obvious admonition, though, is that individual species can greatly (at least by a factor of 2 ) deviate from the average relation for the taxon; if such species happen to dominate a community, the use of equations as given here is of little utility (cf. simulation model by Frost, 1980).

\section{Caveats}

It would be unwise to go much beyond the above statements and especially, to take the values for a and $b$ in Table 1 too seriously. First and most importantly, there may be a bias (systematic error) in the original data. The papers reviewed here estimated oxygen consumption after removing food from the experimental animals: this holds also for the articles used by Dewey (1976) in the equation for unicellular heterotrophs in Table 1 and Fig. 2 (endogenous respiration rates). The approach is likely to lead to a reduction of metabolic rate but since most of the data used here were based on manometric measurements with successive readings to check the constancy of the rate, drastic changes if any would have to have occurred in approximately the first half to two hours, between removal from the food source and the first reading. On the basis of observations reviewed below, I cannot exclude an underestimate of respiration rates by the equations in Table 1 by a factor of 2 or more for the unicellular species, and by a factor of less than 2 for the small metazoans. Neither bias would alter the principal points of this paper. For heterotrophic protozoans, J. M. Dewey (pers. comm. of literature-derived data) also gathered oxygen consumption rates for osmo- or phagotrophically feeding cells or cultures at $20^{\circ} \mathrm{C}$ (i.e. for exogenous respiration). Within 9 species ( 1 with 2 strains) I find that the mean ratio of exogenous over endogenous respiration is 4.2 (S.D., 3.5; median, 3.4; range 1.1 to 11.0 ). In contrast, Dewey (1976) determined a ratio of about 2 for the large dinoflagellate Noctiluca miliaris after $24 \mathrm{~h}$ without food, but measured only a small decline for the normal length of measurements of oxygen uptake. The nutritional status of protozoans under field conditions is not well known. I have inferred that ciliates in the average situation in the marine pelagial are severely food-limited (Banse, 1982) so that at least for them, the equation presented here might remain relevant.

Similar comparative material is scarce for small metazoans. Zeuthen (1947) observed occasionally a continuous decline of oxygen uptake and named lack of food as one possible cause. He regarded the elimination of food-associated, elevated metabolism as a virtue of his data, making them more comparable to the basal metabolism of larger animals on which the ordinary equations for mass dependence of respiration are based. The observations for starvation effects in planktonic copepods for periods of about half a day are ambiguous (Marshall, 1973; Ikeda, 1977a, b; Le Borgne, 1979); effects if any, seem to be slight. For benthic meiofauna, Santmyer (1956) observed an approximate halving of the rate of oxygen uptake in a nematode following $24 \mathrm{~h}$ of starvation (which is much longer than most respiration measurements last). Conversely, Vernberg et al. (1977) reported for a sanddwelling copepod that absence of sand in the respiration chamber enhanced oxygen uptake by $53 \%$. Thus, a number of sources of bias may be hidden in respiration measurements. However, the comparison of pelagic and meiobenthic copepods in Fig. 2 which, because of similar size, might show similar reactions to 
starving suggests that the difference in the proportionality Coefficient $a$ between the larger and smaller metazoans treated here is not an artifact.

Second, the confidence intervals of the equations are appreciable. They may be caused by experimental technique as discussed and/or real differences in oxygen uptake among species of the same mass. Further, groupings by modes of life within nematodes yield markedly different proportionality Coefficients a (Klekowski et al., 1972; Ott and Schiemer, 1973) but the number of species from each of these groupings utilized here for the nematode equation was not controlled, i.e. was arbitrary (see Banse et al., 1971, and Petersen, 1981, for ecological differences among other invertebrates); improper grouping or lumping will contribute to variability.

Third, variability is introduced by the choice of the independent variable, the body mass. For example, the median mass of experimental animals was used for the enchytraeid equation in Table 1 and Fig. 2 (see 'Methods'). If instead, body mass of large specimens is employed, the exponent of the respiration equation becomes 0.88 (C.I., 0.79 to 0.96 ) rather than 0.85 as in Table 1 ; the calculated rates of oxygen uptake of animals of equal mass would then be about 17 and $4 \%$ higher at the lower and upper ends, respectively, of the mass range of concern. This raises the general question: Which ontogenetic size range is representative or preferable in inter-specific comparisons of taxa where adult masses vary widely, as for instance in annelids, bivalves and fishes (Zeuthen, 1953: Fig. 5; 1970: Fig. 7)? Further, the use of wet masses for individual species of mites (rather than of an average conversion factor) yielded a relation between oxygen uptake and wet body mass with an exponent of 0.73 instead of 0.67 as in Table 1 (the exponents do not differ significantly as is also true for the comparison between median and large body masses of enchytraeids). Ikeda (1970: Table 4) provides other examples for this issue. Thus, before new compilations of the kind presented in Table 1 are made, it would be wise to test whether the wet mass/dry mass ratio, e.g. in nematodes, is linear or mass-dependent as in metazoan eggs (Strathmann and Vedder, 1977). If the ratio is non-linear, the exponents of the respiration-body mass relation would be altered accordingly. Finally, it seems undesirable to use raw, individual measurements (as in Banse et al., 1971; Ivleva, 1980) for equations which describe betweenspecies relations unless the number of points for each species is the same and thus no unintentional weighting of the equations is involved.

Fourth and last, the exponent of mass dependence of oxygen uptake may depend on temperature. It increases from about 0.6 at somewhat below $30^{\circ} \mathrm{C}$ to about 0.8 at $0^{\circ} \mathrm{C}$ among crustaceans (Ivleva, 1980) and planktonic animals in general (Ikeda, 1974; cf. recalculation of his crustacean data by Laws and Archie, 1981, and by Vidal and Whitledge, 1982: Table 2). A similar trend is apparent for an oyster (Dame, 1972), within fish species (Prosser, 1973: p. 194), and within an intertidal amphipod (Venables, 1981). For a nematode, however, the exponent increased with temperature (Laybourn, 1979). Temperature dependence of the exponent was not observed among planktonic crustaceans by Vidal and Whitledge (1982; see also intraspecific trends in Collembola [Peterson, 1981: Table 1]).

These issues suggest the need for a wholesale review of mass dependence of respiration rate among invertebrates rather than continued adding of new data. I wonder whether Hemmingsen (1960) was right in calculating one line comprising invertebrates and poikilothermic vertebrates; with the data available to him, there was little reason not to do so (cf. his Figs. 7, 8) except that Winberg (e.g. 1956, cited from Winberg, 1976) pointed out already the high proportionality Coefficient $a$ of fish. Hemmingsen had also noted that the low a values for intraspecific respiration/mass equations of some invertebrate species - e.g. turbellarians, earthworms and leeches - with wet mass up to several $g$ fell well below his poikilotherm line. The same holds for the invertebrate data in Banse et al. (1971; note that their equation on p. 37 should have contained a positive $c$ term, and that all $c$ values in Table 2 should have been negative). Thus, smaller groupings than in Hemmingsen (1960) should be compared. Further, statistical effects on the exponents of allometric equations by error (variability) in the independent variable should be considered (Jolicoeur and Heusner, 1971; Jolicoeur, 1975; Ricker, 1975); the error can be serious unless large mass ranges are studied. Finally, it may be desirable to use non-linear fitting procedures on the untransformed data (cf. Glass, 1969).

\section{Developmental Stages}

So far in this paper, mass-scaled rates were related to the mass of adults. Further, the hypothesis of a predation refuge afforded by small size was established by comparing population production rates. However, if the refuge operates on small physical size as such, it may extend also to developmental stages of a species, as already suggested by Banse and Mosher (1980) and supported by evidence regarding nauplii of pelagic copepods: small nauplii suffered lower predation mortality than larger ones of the same species (see also experimental data in Lewis, 1979: p. 104, on lower mortality of younger stages within species). Now, if reduced predation pressure on populations of small 
species ultimately leads to a reduction of oxygen uptake of adults as described above, developmental stage falling into the appropriate size range might show the same effect of an oxygen uptake lowered relative to the prediction from the allometric equation for the large stages. Indeed, nauplii of 4 species of pelagic copepods (Klekowski and Shushkina, 1966; Epp and Lewis, 1980) have appreciably lower rates of mass-scaled oxygen uptake than their copepodites. The reduction of naupliar metabolism may be present in a 5th species (only at 1 out of 5 temperatures, Laybourn-Parry and Strachan, 1980) but was not observed in 2 other species (Newrkla, 1978; Teare and Price, 1979).

These examples might be taken as supporting the generality of lowered metabolic rates for smaller metazoan species. Alternatively, the lowered rates and a mass dependence with an exponent near unity, may be nothing but a general phenomenon also observed in the ontogeny of larger metazoans (see Zeuthen, 1953, 1970; Prosser, 1973; Epp and Lewis, 1980, for discussion; Wilkie, 1977, for data on man, and reference to fishes; and Riisgård et al., 1980 for a mussel).

\section{INTRINSIC GROWTH RATES OF METAZOANS}

\section{Results}

The principal results of this first review of mass dependence of intrinsic growth rates of very small metazoans are illustrated in Fig. 4: There is no simple relation among the species of the benthic meiofauna and the taxa of the smallest planktonic metazoans; among the benthic species, however, the majority shows marked reduction below the expectation from the general invertebrate line.

Specifically, the $r_{m}$ values of the meiobenthic hydrozoan and all meiobenthic nematodes are well below the mass-scaled rates for the large invertebrates and actually well below an extension of the protozoan line (Fig. 4). One saprophagous, free-living nematode, however, reaches an $r_{m}$ above $1.1 \mathrm{~d}^{-1}$, and the resulting scatter in the nematode values mitigated against calculating a regression equation. The depicted low meiobenthic nematode data are supported by a number of estimated values: Chromadorita tenuis, of $1 \mathrm{ug}$ wet mass, may possess an $r_{\mathrm{m}}$ of $0.07 \mathrm{~d}^{-1}$ (see 'Methods'). Similarly, Monhystera filicaudata with a wet mass of approximately $0.03 \mu \mathrm{g}$ (estimated from Schuurmans Steekhoven, 1935) can under the best of circumstances, i.e. a temperature well above $20^{\circ} \mathrm{C}$, have achieved only about $0.12 \mathrm{~d}^{-1}$ (from Tietjen, 1967). For 4 additional species studied by $\mathrm{v}$. Thun (see

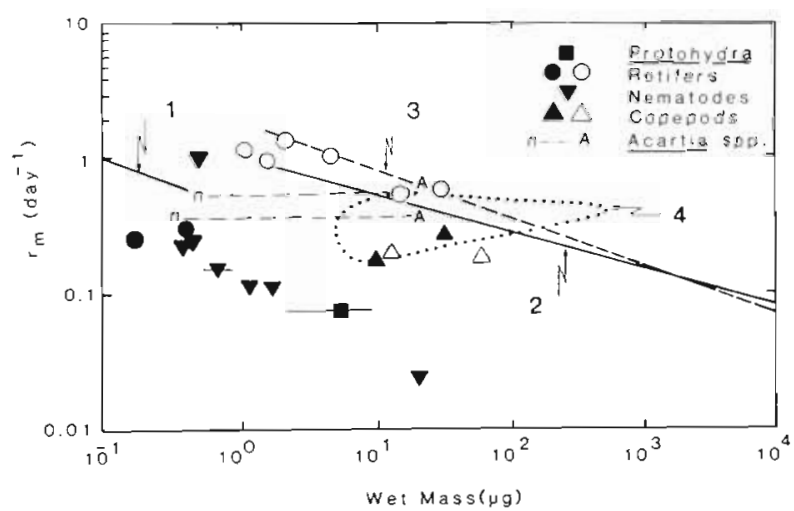

Fig. 4. Intrinsic growth rate as function of wet body mass at $20^{\circ} \mathrm{C}$. (1) Unicellular species; (2) poikilotherms (both from Fenchel, 1974); (3) larger invertebrates calculated from Fenchel (1974; see 'Methods'); (4) envelop for cladocerans (from Fig. 5, converted to wet mass). Full symbols, meiobenthos; open symbols and Acartia spp., plankton (n, first nauplius; A adults). Horizontal lines indicate ranges of mass

'Methods') I estimate $r_{m}$ values of approximately 0.10 to $0.12 \mathrm{~d}^{-1}$ for 3 , and $0.03 \mathrm{~d}^{-1}$ for 1 species. Finally, the low egg numbers (sex ratios not known) and long average generation times for 6 additional species in Zaika and Makarova (1979: Table $1 ; 20^{\circ} \mathrm{C}$ values) do not lend themselves to high $r_{m}$ values either $(<0.12$ with 1 exception which still is $<0.2 \mathrm{~d}^{-1}$ ). In contrast, I estimate a rate of 0.23 to $0.26 \mathrm{~d}^{-1}$ for Plectus palustris, of $1.5 \mu \mathrm{g}$ wet mass at first maturity, from measurements at high food concentrations but without considering mortality prior to maturity (see 'Methods'). Perhaps it is significant that this species, as well as Caenorhabditis briggsae with an $\mathrm{r}_{\mathrm{m}}$ of $1.14 \mathrm{~d}^{-1}$, is hermaphroditic.

The 2 data points for benthic harpacticoid copepods (Fig. 4) are also below the ceiling suggested by the invertebrate regression line but are similar to those of planktonic crustaceans. Other low $r_{m}$ values for benthic harpacticoids at $20^{\circ} \mathrm{C}$, not accompanied by mass data, follow: Paronychocamptus nanus, $0.113 \mathrm{~d}^{-1}$ (Heip, 1977); Tisbe persimilis and T. reluctans, 0.098 and $0.114 \mathrm{~d}^{-1}$ (Volkmann-Rocco and Fava, 1969; both values adjusted for $20^{\circ} \mathrm{C}$ [see 'Methods' under Euterpinal); and roughly $0.15 \mathrm{~d}^{-1}$ for Tigriopus japonicus (from Takano, 1971, see 'Methods'). Also the $r_{m}$ for Scottolana canadensis cultured by Harris (1977) can barely have been above $0.10 \mathrm{~d}^{-1}$, and the rate of the meiobenthic Microarthridion littorale cannot be much higher than $0.07 \mathrm{~d}^{-1}$ (see 'Methods'). Larger values, however, of 0.21 and $0.32 \mathrm{~d}^{-1}$ were estimated for Tisbe clodiensis and $T$. dobshanskii (adjusted to $20^{\circ} \mathrm{C}$ as above; Volkmann-Rocco and Fava, 1969, as improved by Volkmann-Rocco and Battaglia, 1972), and of $0.3 \mathrm{~d}^{-1}$ by Gaudy and associates for $T$ holothuriae (see 'Methods'). Note also that Feller (1980) several times observed $r_{m}$ values between 0.10 and $0.15 \mathrm{~d}^{-1}$ (once 
above 0.2) for Huntemannia jadensis, with about 30 to $75 \mu \mathrm{g}$ adult wet mass, at a cool-temperate field site where the daily average temperatures hardly ever approached $20^{\circ} \mathrm{C}$. Thus, the harpacticoid data do not show clear trends.

The small benthic rotifers Lecane inermis and $L$. tenuiseta have quite low $\mathrm{r}_{\mathrm{m}}$ values, near $0.3 \mathrm{~d}^{-1}$. For the non-pelagic Notommata copeus, Pourriot and Clément (1975) reported an $\mathrm{r}_{\mathrm{m}}$ of $0.47 \mathrm{~d}^{-1}$ at $23^{\circ} \mathrm{C}$. Similarly, the sedentary species Floscularia conifera, studied by Edmondson (1945), must have a very low intrinsic growth rate. For other sessile or benthic rotifers, very low numbers of eggs were observed (Remane, 1929) which were not accompanied by extraordinarily short generation times (cf. Edmondson, 1946: Table 1). Hence, the $r_{m}$ values must be low.

In contrast, the 6 points in Fig. 4 for planktonic rotifers are clearly as high as one would expect if a single allometric equation is valid for all invertebrates. Similarly high values can be gleaned (see 'Methods') for unfertilized mictic females of Epiphanes senta (planktonic in temporary pools) and the sluggish Proales sordida (from a genus with epizoic and epiphytic members).

Intrinsic growth rates for planktonic cladocerans at $20^{\circ} \mathrm{C}$ (Fig. 5) do not show dependence on mass at first maturity. Similar $r_{m}$ values can be read for 3 other cladoceran species from Allan and Goulden (1980: Fig. 9). The same absence of mass dependence is found when $r_{m}\left(20^{\circ} \mathrm{C}\right.$ ) is plotted on mean adult mass (not shown), or $r_{m}\left(15^{\circ} \mathrm{C}\right.$; Fig. $\left.5 b\right)$ and $r_{m}\left(25^{\circ} \mathrm{C}\right.$; not shown $)$ on mass at first maturity. The $\mathrm{r}_{\mathrm{m}}$ values of the 4 pelagic copepods (Fig. $5 a$, b) are indistinguishable from those of the cladocerans and likewise do not suggest a pronounced dependence on mass.

Finally, the consequences of lowered predation pressure inferred by the predation refuge hypothesis are illustrated for developmental stages of 2 species of the pelagic copepod genus Acartia. These species have age-independent specific growth rates (Miller et al., 1977) so that the time course of formation of new organic matter by an individual is like that by a protozoan culture unlimited in food. Thus, it is appropriate to compare an instantaneous growth rate for a metazoon with protozoan $r_{m}$ values which are properties of populations. The specific growth rate is taken from the $20^{\circ} \mathrm{C}$ - plots of mass on time during the ontogeny of a specimen, for $A$. clausi from Landry (1978) and $A$. tonsa from Miller et al. (1977). Fig. 4 demonstrates that indeed, nauplii and copepodites of the 2 Acartia species grow slowly relative to other mass-scaled planktonic animals, while the adults fall on the line for the Population $r_{m}$ of larger invertebrates. Instantaneous growth rates for nauplii of 4 other planktonic copepod species with eggs of very approximately $1 \mathrm{ug}$ mass are similarly low at comparable temperatures (Mullin and Brooks, 1970; Harris and Paffenhöfer, 1976; Paffenhöfer and Harris, 1976 [see critical remark by Vidal 1980: p. 208 on the methodology in the 2 latter papers, suggesting underestimates of rates]).

\section{Discussion}

Meiobenthos

Focussing first on benthic species, Fig. 4 and supporting data in the text show that the optimal growth rates of meiobenthic nematodes are markedly lower than those of other nematodes or groups of small invertebrates. As mentioned, it is too early to tell which form the mass dependence of $r_{m}$ may take for this group, although Fig. 4 suggests a power function for the meiobenthic species with an exponent well below -0.25 . Also the $r_{m}$ values of benthic rotifers seem low; however, recent observations are few. My inferences of low intrinsic rates in benthic rotifers studied by earlier authors but not depicted here are based on low egg numbers (even below 10 female $^{-1}$; egg numbers are genetically fixed and hence little affected by culture conditions) and on observed slow developmental rates or long generation times; but then, the older literature also contains some laboratory observations of low reproductive rates for planktonic rotifers (Edmondson, 1946: Table 1). It is difficult to decide now how much of the calculable low $r_{m}$ is intrinsic and how much is artifact.

Small $r_{m}$ values may be also the rule among cladocerans that are not truly pelagic. The rates for the 5 littoral species in Allan and Goulden (1980: Fig. 9), all belonging to the Chydoridae, are clearly below (by $1 / 3$ to $1 / 2$ ) those of pelagic forms treated here, and by and large even below those of copepods. In contrast, within the copepods considered here, a segregation of rates according to habitat (benthos vs. plankton) or taxonomic relation (harpacticoids vs. calanoids) is not apparent, and the rates of benthic species are only slightly below the general invertebrate line (Fig. 4).

Reduced optimal growth rates among meiobenthic species, relative to those of other animals of the same body mass, were noted by Heip et al. (1978) for a smaller sample (see also brief comment on the subject by Warwick, 1980). Fig. 4 shows that meiobenthic rates may be even lower than those of unicellular organisms of the same mass. Comparisons with protozoons are particularly appropriate because the upper end of the mass range of the equation for one-celled species is weighted by the benthic ciliates investigated by Fenchel (1968). It is not clear how the average metazoan 
would compete when having a growth potential lower than those of the average protozoon with the same mass living in the same habitat. The problem is complicated since metazoans possess quite small developmental stages which may have specific growth rates higher than those of near-adults.

\section{Plankton}

Intrinsic growth rates of planktonic rotifers, cladocerans, and copepods were compared previously by Allan (1976) and Allan and Goulden (1980). Measured $r_{m}$ values for some rotifers at $20^{\circ} \mathrm{C}$ collected here are twice those estimated by Allan (1976), and the rates for cladocerans and copepods are indistinguishable, also in contrast to Allan (cf. Allan and Goulden, 1980: Figs. 9 and 10). These new data weaken some of the ecological and evolutionary inferences by Allan.

When the pattern for planktonic species (Fig. 5) is compared with those for the predominantly benthic taxa (Fig. 4), it seems that their mortality, lowered

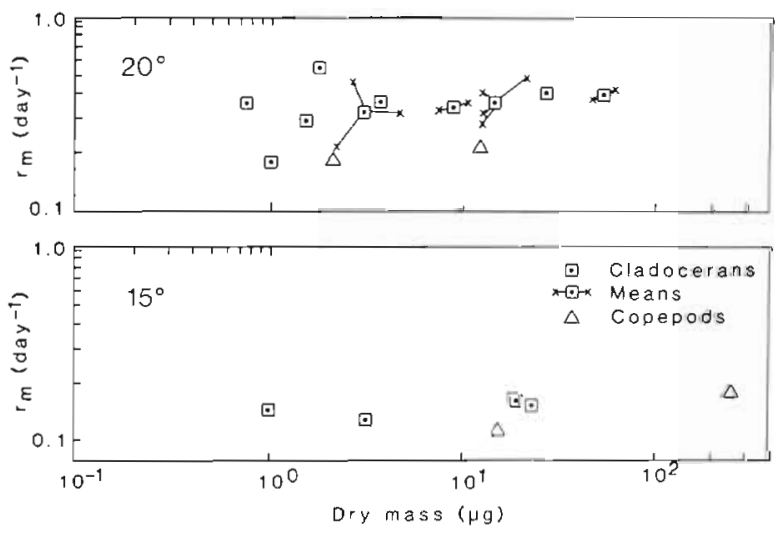

Fig. 5. Intrinsic growth rate of planktonic cladocerans and copepods as function of dry body mass (mass at first maturity for cladocerans), at $20^{\circ} \mathrm{C}$ (Fig. $5 \mathrm{a}$ ) and $15^{\circ} \mathrm{C}$ (Fig. 5b)

relative to that by larger invertebrates (Banse and Mosher, 1980; Banse, 1982), has not led to a similar, rather general lowering of $r_{m}$ as in the benthos. Particularly, the optimal growth rates of the planktonic rotifers are as high as one may expect from massscaled invertebrates. The deviating forms are the planktonic cladocerans and copepods. Among them is truly remarkable the absence of mass dependence of the intrinsic growth rate among cladocerans over 2 orders of magnitude of body mass (mass at first maturity as well as average adult body mass), a fact stressed little by Allan (1976), Allan and Goulden (1980), and Lynch (1980): An entire pelagic group has freed itself from mass dependence as far as the reproductive potential is concerned, for reasons and by mechanisms discussed by Lynch (1980).

It is worth remembering that we possess few laboratory observations for the larger invertebrates and do not yet know with certainty the mass dependence of their intrinsic growth rates even at $20^{\circ} \mathrm{C}$ (see 'Calculations', under 'Methods'). Among the larger invertebrates, there may be extremely r-selected species which achieve still higher intrinsic growth rates than those studied so far and summarized by the invertebrate line in Fig. 4; also, we may now know more favorable culture conditions that were not available to the earlier investigators. The role of experimental conditions is shown by the following: For the clearly opportunistic, small larvacean Oikopleura dioica (mass at maturity about $2.5 \mu \mathrm{gC} \gtrsim 25 \mu \mathrm{g}$ wet mass), $20^{\circ} \mathrm{C}$-cultures yielded an $r_{m}$ of $0.8 \mathrm{~d}^{-1}$, clearly higher than that at $13.5^{\circ} \mathrm{C}$; however, populations in large field enclosures comprising semi-natural plankton assemblages achieved the same rate already at $11^{\circ}$ to $15^{\circ} \mathrm{C}$, with 1 cohort growing at $1.2 \mathrm{~d}^{-1}$ (King, 1981). Whereas $0.8 \mathrm{~d}^{-1}$ is slightly above the broken line in Fig. 4 , the $20^{\circ} \mathrm{C}$-values for the field study would be well above it, more so than the largest cladocerans in Fig. 5. This example shows how little we know about the subject, and how difficult it will be at present to explain mass dependence rigorously.

\section{Outlook}

In conclusion, no overall patterns similar to that shown in Figs. 1 and 2 emerges for the mass dependence of $r_{m}$, in the size range from large unicellular organisms to small metazoans. There is low mass dependence of growth rates of algae, but not of ciliates in the mass range $<1 \mu$ get mass (Banse, 1982). The understanding of groupings of data as for the small invertebrates will presumably come from careful analyses like that by Lynch (1980) of the similarity of $x_{m}$ in small- and large-sized cladocerans and from generalizations as those by Gould (1977: p. 293). I believe it is premature to assume a common pattern or rule and to calculate a single equation for mass dependence which includes laboratory and field data and extends from the phage to large ungulates, as was done by Blueweiss et al. (1978).

Finally, in my view, while groupings as in Fig. 4 may become reasonably explained on the basis of ecological principles, the issue of mass dependence, if any, of intrinsic growth rates of extremely r-selected species must be relatable to physiological ceilings, and perhaps to the metabolic cost of biosynthesis and growth. Our ignorance about the question of cost or efficiency is demonstrated in the following section. 


\section{NET GROWTH EFFICIENCY}

Data for growth, $g$, and respiration, $q$, can be combined into estimates of net growth efficiency (NGE) by calculating the quotient of $\mathrm{g} /(\mathrm{g}+\mathrm{q})$, thereby neglecting the losses of organic matter from excretion, secretion of mucus, etc. (cf. the caveat by Dagg, 1976). The NGE is of physiological interest: Do faster growth rates require the same energy per unit of production as slow ones when invertebrates grow under optimal conditions (see references in Banse, 1979)? The NGE is also important in respect to the size-efficiency hypothesis which concerns the balance between large and small zooplankton species in the field (Hall et al., 1977).

The NGE would be independent of mass if the exponents of equations describing mass dependence of growth and respiration were the same, and would depend on the ratio of the proportionality coefficients. Neglecting largely the issue of the differences in the exponents (cf. the confidence intervals in Table 1), it seems obvious from the reviewed data that the respiration rate of rotifers, depressed relative to that of larger invertebrates (Fig. 2), and their unaltered optimal $\mathrm{r}_{\mathrm{m}}$ (Fig. 4) should result in a high NGE at the optimal growth rate. The review by Dewey (1976) indicates a trend to elevated values which, however, are not clearly higher than those achieved by other invertebrates. Conversely, the same argument applied to meiobenthic nematodes suggests a greatly reduced NGE. This inference is clearly not borne out by either short-term (days) budgets determined by a variety of methods by Marchant and Nicholas (1974, 1 freshwater species, $38 \%$ NGE), Tietjen (1980, preliminary, for 3 marine species, 78, 80 and remarkably, $97 \% \mathrm{NGE}$ ), and Warwick $\left(1981,1\right.$ marine species, $82 \%$ at $20^{\circ} \mathrm{C}$, with the maximum of $87 \%$ at $15^{\circ} \mathrm{C}$ ), or the life-time budget by Schiemer et al. (1980, 1 freshwater species, about 50 to $70 \%$ ). Finally, with the usual mass dependence of respiration rate apparently also valid for the cladocerans (Sushchenya, 1972: p. 98, Eq. 33; combines within- and between-species datal but obvious mass dependence of $r_{m}$ absent (Fig. 5), the growth efficiency of the average large species should be much higher than that of the small species at optimal growth rates. I am not aware of data suitable to test this supposition.

As stated earlier, oxygen uptake is measured on specimens while the intrinsic growth rate is a population parameter. The resulting equations of mass dependence are therefore not strictly comparable. It would be more consistent to calculate also the oxygen consumption for populations (life-time budgets); to do this, within-species data for mass dependence of metabolism might be applied to mass frequency data found from stable age distributions on which all mea- surements of intrinsic growth rates should be based. Nevertheless, I regard it unlikely that recalculation of existing data would let vanish the mismatch between the observed NGE of nematodes and the inference about their NGE from rates of growth and oxygen uptake. I take this lack of internal consistency of our knowledge about rates of metabolism and intrinsic growth as a symbol for the state of the field: It seems that the answering of questions about the basic size or mass dependence of life is in need of more highquality data as well as of theoretical foundations.

\section{CONCLUSIONS}

The goal of the present paper was to gather, present, and discuss data on mass dependence of rates of oxygen uptake and intrinsic growth. As noted in the 'Introduction', the resulting regression lines permit to recognize rules and exceptions and are therefore useful by themselves. More important, they should form the basis for future attempts to explain rules concerning basic properties of life.

It seems possible now that the well-established respiratory 3/4-power dependence may not hold among invertebrates for all temperatures. Until this issue is settled, further attempts to derive the exponent(s) from first principles may be premature. With present knowledge, the derivation must hold for mammals and unicellular organisms, as well as account for temperature dependence among poikilotherms

For the intrinsic growth rate, the picture is now more obscure than a few years ago. One wonders whether there is o n e rule for small metazoans. Obviously, the data used here were of uneven quality since they were not only affected by problems of measurement - as were the determinations of oxygen uptake - but also by computational difficulties (or at least inconsistencies) in calculating $\mathrm{r}_{\mathrm{m}}$. Even so, it seems unlikely that the large differences revealed within a small range of mass are all artifacts. Finally, new observations of weak mass dependence of intrinsic growth rates among unicellular algae (Banse, 1982) complicate the unresolved question of why there is marked mass dependence of growth among organisms: Possibly, that rule does not apply to some major taxa.

For approaching experimentally or theoretically the reasons for the mass dependence of life it seems that small organisms should be the objects of choice rather than, e.g., the fairly well-explored mammals. For both unicellular species and very small invertebrates, experiments need only to be of small spatial and temporal dimensions because of the small body masses and short generation times; they can thus be rather easily conducted and replicated. Certainly, unicellular organisms will be more amenable to theoretical work 
than metazoans because of their less-complicated organization. Mass dependence beyond the cellular level, however, may raise additional issues and needs to be investigated. For example, this review suggests for the inquiry into mass dependence of multicellular metabolism and growth that very small metazoans may not be exactly scaled-down versions of larger animals; in regard to the principle of mass dependence, i.e. exponents well below unity, they do seem to behave like other animals.

Acknowledgements. This study was partially supported by the U.S. Department of Energy, Contract DE-ATO6-76EV75026 (DE-EV-75026-96), Principal Investigator, G. C. Anderson, Seattle, and the Skidaway Institute of Oceanography, University System of Georgia, in Savannah, Director, D. W. Menzel. J. M. Dewey helped with newer rotifer data and other aspects of this review. W $\mathrm{T}$ Edmondson pointed out earlier work on rotifers, and several colleagues named in the text provided raw data. S. Findlay, D. W Menzel and 3 anonymous reviewers suggested numerous improvements of earlier versions of the manuscript, and A. Chesney, D. McCauley, and S. McIntosh in Savannah, and M. Peacock in Seattle helped with literature search, typing, and graphical work. This support and assistance is gratefully acknowledged.

Contribution No. 1277, School of Oceanography, University of Washington, Seattle, Washington, USA.

\section{LITERATURE CITED}

Allan, J. D. (1976). Life history patterns in zooplankton. Am. Nat. 110: 165-180

Allan, J. D., Goulden, C. E. (1980). Some aspects of reproductive variation among freshwater zooplankton. In: Kerfoot, W. C. (ed.) Evolution and ecology of zooplankton communities. University Press of New England, Hanover, New Hampshire, pp. 380-410

Alongi, D. M. Tietjen, J. H. (1980). Population growth and trophic interactions among free-living marine nematodes. In: Tenore, K. R., Coull, B.C. (eds.) Marine benthic dynamics. University of South Carolina Press, Columbia, S. C., pp. 151-166

Atkinson, H. J. (1973). Respiratory physiology of the marine nematodes Enoplus brevis (Bastian) and E. communis (Bastian). I. The influence of oxygen tension and body size. J. exp. Biol. 59: 255-266

Atkinson, H. J. (1976). The respiratory physiology of nematodes. In: Croll, N. A. (ed.) The organization of nematodes. Academic Press, London-New York, pp. 243-272

Banse, K. (1979). On weight dependence of net growth efficiency and specific respiration rates among field populations of invertebrates. Oecologia (Berl.) 38: 111-126

Banse, K. (1982). Cell volumes, maximal growth raters of unicellular algae and ciliates, and the role of ciliates in the marine pelagial. Limnol. Oceanogr. 27, in press

Banse, K., Mosher, S. (1980). Adult body mass and annual production/biomass relationships of field populations. Ecol. Monogr 50: 355-379

Banse, K., Nichols, F. H., May, D. R. (1971). Oxygen consumption by the sea bed. III. - On the role of the macrofauna at three stations. Vie Milieu 22 (Suppl.): 31-52

Blueweiss, L., Fox, H., Kudzma, V., Nakashima, D., Peters, R., Sams, S. (1978). Relationship between body size and some life history parameters. Oecologia (Berl.) 37: 257-272
Blum, J. J. (1977). On the geometry of four-dimensions and the relationship between metabolism and body mass. J. theor. Biol. 64: 599-601

deConinck, L. A., Schuurmans Steekhoven, J. H., Jr. (1933). The freeliving marine nemas of the Belgian coast. II. Mém. Mus. R. Hist. nat. Belg. 58: 1-163

Coull, B. C., Vernberg, W B. (1970). Harpacticoid copepod respiration: Enhydrosoma propinquum and Longipedia helgolandica. Mar. Biol. 5: 341-344

Curl, H., Jr. (1962). Standing crop of carbon, nitrogen, and phosphorus and transfer between trophic levels, in continental shelf waters south of New York. Rapp. P.-v. Cons. intern. Explor. Mer 153: 183-189

Dagg, M. J. (1976). Complete carbon and nitrogen budgets for the carnivorous amphipod, Calliopius laeviusculus (Krøyer). Int. Revue ges. Hydrobiol. 61: 297-357

Dame, R. F. (1972). The ecological energies of growth, respiration and assimilation in the intertidal American oyster Crassostrea virginica. Mar. Biol. 17: 243-250

Dewey, J. M. (1976). Rates of feeding, respiration, and growth for the rotifer Brachionus plicatilis and the dinoflagellate Noctiluca miliaris in the laboratory. Ph. D. thesis, University of Washington, Seattle

Doohan, M. (1973). An energy budget for adult Brachionus plicatilis Müller (Rotatoria). Oecologia (Berl.) 13: 351-362

Dumont, H. J., van der Velde, I., Dumont, S. (1975). The dry weight estimate of biomass in a selection of Cladocera, Copepoda and Rotifers from the plankton, periphyton and benthos of continental waters. Oecologia (Berl.) 19: 75-97

Edmondson, W. T. (1945). Ecological studies of sessile Rotatoria, part. II. Dynamics of populations and social structures. Ecol. Monogr. 15: 141-172

Edmondson, W T. (1946). Factors in the dynamics of rotifer populations. Ecol. Monogr. 16: 357-372

Epp, R. W., Lewis, W M., Jr. (1980). The nature and significance of metabolic changes during the life history of copepods. Ecology 61: 259-264

Feller, R. J. (1980), Quantitative cohort analysis of a sanddwelling meiobenthic harpacticoid copepod. Estuar coast. mar. Sci. 11: 459-476

Fenchel, $T$ (1968). The ecology of marine microbenthos. III The reproductive potential of ciliates. Ophelia 5: 123-136

Fenchel, $T$ (1974). Intrinsic rate of natural increase: the relationship with body size. Oecologia (Berl.) 14: 317-326

Fenchel, $T$ (1978). The ecology of micro- and meiobenthos. Ann. Rev. Ecol. Syst. 9: 99-121

Fenchel, T (1980). Suspension feeding in ciliated Protozoa: Feeding rates and their ecological significance. Microb. Ecol. 6: 13-25

Ferris, J. C. (1932). A comparison of the life histories of mictic and amictic females in the rotifer, Hydatina senta. Biol. Bull. mar, biol, Lab., Woods Hole 63: 442-455

Findlay, S. E. G. (1981). Effects of nematodes on detrital dynamics. Ph. D. thesis, University of Georgia, Athens

Findlay, S. E. G. (1982). Effect of nutritional quality on population dynamics of a marine nematode (Dipiolaimella chitwoodi). Mar Biol. 68: 223-227

Foulds, J. B., Roff, J. C. (1976). Oxygen consumption during simulated vertical migration in Mysis relicta (Cnustacea, Mysidacea). Can. J. Zool. 54: 377-385

Frank, P. W., Ball, C. D., Kelly, R. W. (1957). Vital statistics of laboratory cultures of Daphnia pulex de Geer related to density. Physio] Zool. 30: 287-305

Frost, B. W. (1980). The inadequacy of body size as an indicator of niches in zooplankton. In: Kerfoot, W. C. (ed.) Evolution and ecology of zooplankton communities. Uni- 
versity Press of New England, Hanover, New Hampshire, pp. $742-753$

Galkovskaya, G. Q. (1963). Utilization of food for growth and conditions of maximum production of the rotifer Brachionus calyciflorus Pallas. (Russ.) Zool. Zh. 42: 506-512

Gaudy, R., Guérin, J.-P. (1977). Dynamique des populations de Tisbe holothuriae (Crustacea: Copepoda) en élèvage sur trois régimes artificiels différents. Mar Biol. 39: $137-145$

Gaudy, R., Guérin, J.-P. (1978). Étude expérimentale de la respiration de la croissance et la fecondité de Tisbe holothuriae (Copépode: Harpacticoidea) élevé à des températures differentes. In: McLusky, D. S., Berry, A. J. (eds.) Physiology and behaviour of marine organisms. Pergamon, Oxford, pp. 31-38

Gaudy, R., Guérin, J.-P., Moraitou-Apostolopoulou, M. (1982). Effect of temperature and salinity on the population dynamics of Tisbe holothuriae Humes (Copepoda: Harpacticoidea) fed on two different diets. J. exp. mar. Biol. Ecol. 57: 257-271

Gerlach, S. A. (1971). On the importance of marine meiofauna for benthos communities. Oecologia (Berl.) 6: 176-190

Gilbert, J. J. (1976). Polymorphism in the rotifer Asplanchna sieboldi: biomass, growth, and reproductive rate of the saccate and campanulate morphotypes. Ecology 57 : $542-551$

Glass, N. R. (1969). Discussion of calculation of power functions with special reference to respiratory metabolism in fish. J. Fish. Res. Bd Can. 26: 2643-2650

Gould, S. J. (1977). Ontogeny and phylogeny, Belknap/Harvard University Press, Cambridge, Mass

Hall, D. J., Threlkeld, S. T., Burns, C. W., Crowley, P. H. (1977). The size-efficiency hypothesis and the size structure of zooplankton communities. Ann. Rev. Ecol. Syst. 7: $177-208$

Harris, R. P. (1977). Some aspects of the biology of the harpacticoid copepod, Scottolana canadensis (Willey), maintained in laboratory culture. Chesapeake Sci. 18: 245-252

Harris, R. P., Paffenhöfer, G.-A. (1976). Feeding, growth and reproduction of the marine planktonic copepod Temora longicornis Müller. J. mar. biol. Ass. U. K. 56: 657-690

Heip, C. (1977). On the evolution and reproductive potentials in a brackish water meiobenthic community. Akad. Wiss. Lit. Mainz, Math. Naturw. Kl., Microfauna Meerenbodens 61: $105-112$

Heip, C. (1978). The calculation of eliminated biomass. Biol. Jaarb. 44: 217-225

Heip, E., Smol, N. (1976). Influence of temperature on the reproductive potential of two brackish-water harpacticoids (Crustacea: Copepoda). Mar. Biol. 35: 327-334

Heip, C., Smol, N., Absillis, V. (1978). Influence of temperature on the reproductive potential of Oncholaimus oxyuris (Nematoda: Oncholaimidae). Mar Biol. 45: 255-260

Hemmingsen, A. M. (1960). Energy metabolism as related to body size and respiratory surfaces, and its evolution. Rep. Steno meml. Hosp. 9 (2): 1-110

Hummon, W. D., Bevelhymer, D. P. (1980). Life table demography of the rotifer Lecane tenuiseta under culture conditions and various age distributions. Hydrobiologia 70 $25-28$

Ikeda, I. (1970). Relationship between respiration rate and body size in marine plankton animals as a function of the temperature of habitat. Bull. Fac. Fish. Hokkaido Univ. 21 91-112

Ikeda, T. (1974). Nutritional ecology of zooplankton. Mem. Fac. Fish. Hokkaido Univ. 22 (1): 1-97
Ikeda, T. (1977a). The effect of laboratory conditions on the extrapolation of experimental measurements to the ecology of marine zooplankton. Bull. Plankton Soc. Japan 24 29-35

Ikeda, $\mathrm{T}$ (1977b). The effect of laboratory conditions of experimental measurements to the ecology of marine zooplankton. IV. Changes in respiration and excretion rates of boreal zooplankton species maintained under fed and starved conditions. Mar. Biol. 41.241-252

Ivleva, I. V. (1980). The dependence of crustacean respiration rate on body mass and habitat temperature. Int. Revue ges Hydrobiol, 65: 1-47

Jennings, H. S., Lynch, R. S. (1928). Age, mortality, fertility, and individual diversities in the rotifer Proales sordida Gosse. II. Life-history in relation to mortality and fecundity. J. exp. Zool. 39: 339-381

Johannes, R. E. (1964). Phosphorus excretion and body size in marine animals: microzooplankton and nutrient regeneration. Science, N. Y. 146: 923-924

Jolicoeur, P. (1975). Linear regression in fisheries research some comments. J. Fish. Res. Bd Can. 32: 1491-1494

Jolicoeur, P., Heusner, A. A. (1971). The allometry equation in the analysis of the standard oxygen consumption and body weight of the white rat. Biometrics 27: 841-855

King, C. E. (1967). Food, age, and the dynamics of a laboratory population of rotifers. Ecology 48: 111-128

King, C. E. (1970). Comparative survivalship and fecundity of mictic and amictic female rotifers. Physiol. Zool. 43: 200-212

King, C. E. (1972). Adaptation of rotifers to seasonal variation. Ecology 53: 408-418

King, K. R. (1981). The quantitative natural history of Oikopleura dioica (Urochordata: Larvacea) in the laboratory and in enclosed water columns. Ph. D. thesis, University of Washington, Seattle

Kinne, O. (1977). Cultivation of animals: research cultivation. In: O. Kinne (ed.) Marine ecology, Vol. 3, Cultivation, Part 2. Wiley, London, pp. 579-1293

Khlebovich, T V (1974). Respiration intensity of ciliates of various body size. (Russ.) Tsitologiya 16: 103-106

Klekowski, R. Z., Shushkina, E. A. (1966). Ernährung, Atmung, Wachstum und Energie-Umformung in Macrocyclops albidus (Jurine) Verh. Int. Verein. Limnol. 16: 399-418

Klekowski, R. Z., Wasilewska, L., Paplinska, E. (1972). Oxygen consumption by soil-inhabiting nematodes. Nematologica 18: 391-403

Klyashtorin, L. B., Kuz'micheva, V. I. (1976). Level of energy expenditure of planktonic crustaceans on active movements. Oceanology 15: 592-595 (Trans. from Okeanologiya 15, 1975)

Krogh, A. (1916). The respiration exchange of animals and man, Longmans Green, London

Landry, M. R. (1978). Population dynamics and production of a planktonic marine copepod. Acartia clausi, in a small temperate lagoon on San Juan Jsland, Washington. Int. Revue ges. Hydrobiol. 63: 77-119

Lasker, R., Wells, J. B. J., McIntyre, A. D. (1970). Growth, reproduction, respiration, and carbon utilization of the sand-dwelling harpacticoid copepod, Asellopsis intermedia. J mar biol. Ass. U. K. 50: 147-160

Lasserre, P. (1971). Données écophysiologiques sur la répartition des oligochètes marins meiobenthiques. Incidence des paramètres salinité, température, sur la métabolisme respiratoire de deux espèces euryhalines du genre Marionina Michaelsen 1889 (Enchytraeidae, Oligochaeta). Vie Milieu 22 (Suppl.): 523-540 
Lasserre, P., Renaud-Momant, J. (1971). Consommation d'oxygène chez un crustacé méiobenthi-interstitiel de la sous classe des Mystacocarides. C. r. Acad. Sci. Paris 272: $1011-1014$

Lasserre, P., Renaud-Mornant, J. (1973). Resistance and respiratory physiology of intertidal meiofauna to oxygendeficiency. Netherl. J. Sea Res. 7: 290-302

Laughlin, R. (1965). Capacity for increase: a useful population statistic. J. anim. Ecol. 34: 77-91

Laws, E. A., Archie, J. W. (1981). Appropriate use of regression analysis in marine biology. Mar. Biol. 65: 13-16

Laybourn, J. (1977). Respiratory energy losses in the protozoan predator Didinium nasutum Müller (Ciliophora). Oecologia (Berl.) 27: 305-309

Layboum, J. (1979). The effects of temperature on the respiration and production of the freshwater nematode Anonchus sp. Oecologia (Berl.) 41: 329-337

Laybourn, J. Finlay, B. J. (1976). Respiratory energy losses related to cell weight and temperature in ciliated Protozoa. Oecologia (Berl.) 24: 349-355

Laybourn-Parry, J. Strachan, I. M. (1980), Respiratory metabolism of Cyclops bicuspidatus (sensu stricta) (Claus) (Copepoda: Cyclopoida) from Esthwaite Water, Cumbria. Oecologia (Berl.) 46: 386-390

Le Borgne, R. P. (1979). Influence of duration of incubation on zooplankton respiration and excretion results. J. exp. mar. Biol. Ecol. 37: 127-137

Lewis, W. M., Jr (1979). Zooplankton community analysis Studies in a tropical system, Springer, New York

Luxton, M. (1975). Studies on the oribatid mites of a Danish beech wood soil. II. Biomass, calorimetry, and respirometry. Pedobiol. 15: 161-200

Lynch, M. (1980). The evolution of cladoceran life histories. Quart. Rev. Biol. 55: 23-42

Marchant, R., Nicholas, W. L., (1974). An energy budget for the free-living nematode Pelodera (Rhabditidae). Oecologia (Berl.) 16: 237-252

Marshall, S. M. (1973). Respiration and feeding in copepods. Adv. mar. Biol. 11: 57-120

McAllister, C. D. (1971). Some aspects of nocturnal and continuous grazing by planktonic herbivores in relation to production studies. Fish. Res. Bd Canada, Tech. Rept. 248 1-281. (Also Ph. D. Thesis, Univ. of Washington, Seattle, 1970)

McMahon, T. (1973). Size and shape in biology. Science, N. Y. 179: 1201-1204

Miller, C. B., Johnson, J. K., Heinle, D. R. (1977). Growth rules in the marine copepod genus Acartia. Limnol. Oceanogr 22: $326-335$

Miller, H. M. (1931). Alternation of generations in the rotifer Lecane inermis. Biol. Bull. mar. biol. Lab., Woods Hole 60 34.5-381

Mullin, M. M., Brooks, E. R. (1970). Growth and metabolism of two planktonic, marine copepods as influenced by temperature and type of food. In: Steele, J. H. (ed.) Marine food chains. University of California Press, Berkeley-Los Angeles, pp. $74-95$

Muus, B. J. (1967). The fauna of Danish estuaries and lagoons Distribution and ecology of dominating species in the shallow reaches of the mesohaline zone. Medd. Danmarks Fisk.-Havunders., N. S., 5 (1): 1-315

Muus, K. (1966). Notes on the biology of Protohydra leuckarti Greef (Hydroidea, Protohydridae). Ophelia 3: 141-150

Newrkla, P. (1978). The influence of ionic concentration on population parameters, developmental time, activity, and respiration rate of Arctodiaptomus spinosus (Daday) (Calanoida, Copepoda). Oecologia (Berl.) 33: 87-99
O'Connor, F. B. (1963). Oxygen consumption and population metabolism of some populations of Enchytraeidae from North Wales. In: Doeksen, J., van der Drift, J. (eds.) Soil organisms. North-Holland Publ. Co., Amsterdam, pp. $32-48$

O'Connor, F. B. (1967). The Enchytraeidae. In: Burges, A., Raw, F. (eds.) Soil biology. Academic Press, London-New York, pp. 213-257

Ott, J., Schiemer, F. (1973). Respiration and anaerobiosis of free living nematodes from marine and limnic sediments. Netherl. J. Res. 7: 233-243

Overgaard-Nielsen, C. (1961). Respiratory metabolism of some populations of enchytraeid worms and free-living nematodes. Oikos 12: 17-35

Paffenhöfer, G.-A., Harris, R. P. (1976). Feeding, growth and reproduction of the marine planktonic copepod Pseudocalanus elongatus Boeck. J. mar. biol. Ass. U. K. 56: 327-344

Palmer, M. A. (1980). Variation in life history patterns between intertidal and subtidal populations of a meiobenthic copepod. Mar. Biol. 60: 159-165

Palmer, M. A., Coull, B. C. (1980). The prediction of development rate and the effects of temperature for the meiobenthic copepod, Microarthridion littorale (Poppe). J. exp. mar. Biol. Ecol. 48: 73-83

Petersen, H. (1981). The respiratory metabolism of Collembola species from a Danish beech wood. Oikos 37 273-286

Pilarska, J. (1972). The dynamics of growth of experimental populations of the rotifer Brachionus rubens Ehrbg. Pol Arch. Hydrobiol. 19: 265-277

Platt, T., Silvert, W. (1981). Ecology, physiology, allometry and dimensionality. J. theoret. Biol. 93: 855-860

Pourriot. R. (1973). Influence de la tenus en protéines, de la température, et du jeûne sur la respiration de Rotifères héléoplanctoniques. Verh. Intern. Ver. Limnol. 18: $1429-1433$

Pourriot, R., Clément, P. (1975). Influence de Ia durée de l'éclairement quotidien sur le taux de femelles mictiques chez Notommota copeus Ehr. (Rotifère). Oecologia (Berl.) 22: $67-77$

Pourriot, R., Deluzarches, M. (1970). Sur la consummation d'oxygène par les Rotifères. Ann. Limnol. 6: 229-248

Prejs, K. (1977). The species diversity, numbers and biomass of benthic nematodes in central part of lakes with different trophy. Ecol. Pol. 15: 31-44

Price, R., Warwick, R. M. (1980). The effect of temperature on the respiration rate of meiofauna. Oecologia (Berl.) 44 : $145-148$

Prosser, C. L. (1973). Oxygen: respiration and metabolism. In: Prosser, C. L. (ed.) Comparative animal physiology, 3rd ed.. Sauders, Philadelphia, pp. 165-211

Remane, A. (1929). Rotatoria. In: Grimpe, G. (ed.) Tierwelt Nord-und Ostsee. VII. e. Akadem. Verlagsges., Leipzig

Richman, S. (1958). The transformation of energy by Daphnia pulex. Ecol. Monogr. 28: 275-291

Ricker, W. E. (1975). A note concerning Professor Jolicoeur's comments. J, Fish. Res. Bd Can. 32: 1494-1498

Rippingale, R. J., Hodgkin, E. P. (1974). Population growth of a copepod Gladioferens imparipes Thomson. Aust. J. mar freshwat. Res. 25: 351-360

Riisgård, H. U., Randløv, A., Kristensen, P. S. (1980). Rates of water processing, oxygen consumption and efficiency of particle retention in veligers and young post-metamorphic Mytilus edulis. Ophelia 19: 37-47

Robertson, A. (1968). The continuous plankton recorder: a 
method for studying the biomass of calanoid copepods Bull. mar Ecol. 6: 185-223

Robertson, J. R., Salt, G. W (1981). Responses in growth, mortality, and reproduction to variable food levels by the rotifer, Asplanchna girodi. Ecology 62: 1585-1596

Ruttner-Kolisko, A. (1972). Der Einfluß von Temperatur und Salzgehalt des Mediums auf Stoffwechsel und Vermehrungsintensität von Brachionus plicatilis (Rotatoria). Verh. dt. Zool. Ges. 65: 89-95

Santmyer, P. H. (1956). Studies on the metabolism of Panagrellus redivivus (Nematoda: Cephalobidae). Proc. Helminthol. Soc. Wash. 27: 30-36

Schiemer, F. (1973). Respiration rates of two species of gnathostomulids. Oecologia (Berl.) 13: 403-406

Schiemer, F. (1982a). Food dependence and energetics of freeliving nematodes. I. Respiration, growth and reproduction of Caenorhabditis briggsae (Nematoda) at different levels of food supply. Oecologia (Berl.), in press

Schiemer, F. (1982b). Food dependence and energetics of freeliving Nematodes. II. Life history parameters of Caenorhabditis briggsae (Nematoda) at different levels of food supply. Oecologia (Berl.), in press

Schiemer, F, Duncan, A. (1974). The oxygen consumption of a freshwater benthic nematode, Tobrilus gracilis (Bastian). Oecologia (Berl.) 15: 121-126

Schiemer, F. A., Duncan, A., Klekowski, R. Z. (1980). A bioenergetic study of a benthic nematode, Plectus palustris de Man 1880, throughout its life cycle. II. Growth fecundity and energy budgets at different densities of bacterial food and general ecological considerations. Oecologia (Berl.) 44: 205-212

Schuurmans Steekhoven, J. H., Jr. (1935), Nematoda Errantia In: Grimpe, G. (ed.) Tierwelt Nord- u. Ostsee. V. e Akadem. Verlagsges., Leipzig

Smith, F. F. (1963). Population dynamics in Daphnia magna and a new model of population growth. Ecology 44 : $651-663$

Strathmann, R. R., Vedder, K. (1977). Size and organic content of eggs of echinoderms and other invertebrates as related to developmental strategies and egg eating. Mar. Biol. 39: 305-309

Sushchena, L. M. (1972). On the intensity of respiration in crustaceans. (Russ.) Naukova Dumka, Kiew

Takano, H. (1971). Breeding experiments of a marine littoral copepod Tigriopus japonicus Mori. Bull. Tokai Reg. Fish. Res. Lab. 64: $71-80$

Taylor, W. D., Lean, D. R. S. (1981). Radiotracer experiments on phosphorus uptake and release by limnetic microzooplankton. Can. J. Fish aquat. Sci. 38: 1316-1321

Teal, J. M., Wieser, W. (1966). The distribution and ecology of nematodes in a Georgia salt marsh. Limnol. Oceanogr. 11: $217-222$

Teare, M., Price, R. (1979). Respiration of the meiobenthic harpacticoid copepod, Tachidius discipes Giesbrecht, from an estuarine mudflat. J. exp. mar. Biol. Ecol. 41: 1-8

Tietjen, J. H. (1967). Observations on the ecology of the marine nematode Monhystera filicaudata Allgen 1929 Trans. Am. microsc. Soc. 86: 304-306

Tietjen, J. H. (1980). Microbial-meiofaunal interrelationships: a review. In: Schlessinger, D. (ed.) Microbiology 1980 Am. Soc. Microbiol. Washington, D. C., 335-338

Tietjen, J. H., Lee, J. J. (1977). Life histories of marine nematodes. Influence of temperature and salinity on the reproductive potential of Chromadorina germanica Bütschli. Akad. Wiss, Lit. Mainz, Math. Nat. Kl., Mikrofauna Meeresbodens 61: 263-270
Thomson, J. M. (1946). New crustacea from the Swan River estuary. J. Proc. R. Soc. West. Aust. 30: 35-53

Venables, B. J. (1981). Oxygen consumption in a tropical beach amphipod, Talorchestia margaritae Stephensen: effects of size and temperature. Crustaceana 41:90-94

Vernberg, W. B., Coull, B. C., Jorgensen, D. D. (1977). Reliability of laboratory and metabolic measurements of meiofauna. J. Fish. Res. Bd Can. 34: 164-167

Vidal, J. (1980). Physioecology of zooplankton. IV Effects of phytoplankton concentration, temperature, and body size on the net production efficiency of Calanus pacificus. Mar Biol. 56: 203-211

Vidal, J., Whitledge, T. E. (1982). Rates of metabolism of planktonic crustaceans as related to body weight and temperature of habitat. J. Plankton Res. 4: 77-86

Volkmann-Rocco, B., Battaglia, B. (1972). A new case of sibling species in the genus Tisbe (Copepoda, Harpacticoidea). In: Battaglia, B. (ed.) Proceedings of Fifth European Marine Biology Symposium. Piccin, Padua-London, pp. $67-80$

Volkmann-Rocco, B., Fava, G. (1969). Two sibling species of Tisbe (Copepoda, Harpacticoidea): Tisbe reluctans and $T$. persimilis n. sp. Research on their morphology and population dynamics. Mar. Biol. 3: 159-164

Warwick, R. M. (1980). Population dynamics and secondary production of benthos. In: Tenore, K.R., Coull, B. C. (eds.) Marine benthic dynamics. University of South Carolina Press, Columbia, S. C., pp. 1-24

Warwick, R. W. (1981). The influence of temperature and salinity on energy partitioning in the marine nematode Diplolaimella bruciei. Oecologia (Berl.) 51: 318-325

Warwick, R. M., Price, R. (1979). Ecological and metabolic studies on free-living nematodes from an estuarine mudflat. Estuar coast. mar. Sci. 9: 257-271

Wieser, W., Kanwisher, J. (1960). Growth and metabolism in a marine nematode, Enoplus communis Bastian. Z. vergl. Physiol. 43: 29-36

Wieser, W., Kanwisher, J. (1961). Ecological and physiological studies on marine nematodes from a small salt marsh near Woods Hole, Mass. Limnol. Oceanogr. 6: 262-270

Wieser, W., Schiemer, F. (1977). The ecophysiology of some marine nematodes from Bermuda: seasonal aspects. $J$. exp. mar Biol. Ecol. 26: 97-106

Wilkie, D. R. (1977). Metabolism and body size. In: Pedley, T J. (ed.) Scale effects in animal locomotion. Academic Press, London-New York, pp. 23-36

Winberg, G. G. (1976). Dependence of energy metabolism on body mass in aquatic poikilotherms. (Russ.) Zh. Obshch Biol. 37: 56-70

Winner, R. W., Farrell, M. P. (1976). Acute and chronic toxicity of copper to four species of Daphnia. J. Fish. Res. Bd Can. 33: 1685-1691

Zaika, V. E., Makarova, N. P. (1979). Specific production of freeliving marine nematodes. Mar Ecol. Prog. Ser. 1: $153-158$

Zeuthen, E. (1947). Body size and metabolic rate in the Animal Kingdom with special regard to the marine microfauna. C. r. Trav. Lab. Carlsberg, Sér. Chim. 26: 17-161

Zeuthen, E. (1953). Oxygen uptake as related to body size in organisms. Quart. Rev. Biol. 28: 1-12

Zeuthen, E. (1970). Rate of living as related to body size in organisms. Pol. Arch. Hydrobiol. 17: 21-30

Zurlini, G., Ferrari, I., Nassogne, A. (1978). Reproduction and growth of Euterpina acutifrons (Copepoda: Harpacticoidea) under experimental conditions. Mar. Biol. 46: $59-64$ 